\title{
Physicians' Social Networks and the Use of New Medical Technology
}

\author{
Lara Gardner \\ Dept. of Management and Business Administration, College of Business \\ Southeastern Louisiana University \\ SLU 10813, Hammond, LA, USA \\ Tel: 1-985-549-3068Ｅ-mail: lara.gardner@selu.edu
}

Received: December 28, 2019 Accepted: February 8, 2020 Published: February 11, 2020

doi:10.5296/ieb.v6i1.16445

URL: https://doi.org/10.5296/ieb.v6i1.16445

\begin{abstract}
Recently the U.S. government has generously funded initiatives aimed to generate and/or disseminate results on the clinical- and cost-effectiveness of various medical treatments to physicians. The American Recovery and Reinvestment Act of 2009 provided more than \$1 billion in funding for such comparative effectiveness research (CER). For CER to be a successful investment, new information on the clinical- or cost-effectiveness of a medical method must be transmitted to physicians using methodologies that will effectively change practitioners' behavior. Yet there is limited evidence on the effectiveness of past strategies used to disseminate new information to physicians and some current dissemination strategies fail to address the specific social context in which physicians practice. Our study explores how physicians' social networks are related to the adoption of a treatment for cardiac disease, the drug-eluting stent. Using two different measures of physician networks, all results indicate that physicians with larger networks adopt the drug-eluting stent on a wider scale, even after controlling for physician, patient, hospital, and local characteristics.
\end{abstract}

Keywords: Physicians, Social Networks, Medical technology

\section{Introduction}

The U.S. federal government has devoted a great deal of money and authority to organizations designed to conduct and/or oversee comparative effectiveness research (CER) for medical care products. This includes the American Recovery and Reinvestment Act of 2009 , which authorized $\$ 1.1$ billion more to be spent on CER and directed the Institute of 
Medicine (IOM) to recommend national priorities for CER. The IOM has defined CER as "the generation and synthesis of evidence that compares the benefits and harms of alternative methods to prevent, diagnose, treat, and monitor a clinical condition or improve the delivery of care" (IOM, p. 1). Further organizational efforts were made when the Affordable Care Act of 2010 established a new, nongovernmental entity called the Patient-Centered Outcomes Research Institute to oversee and set guidelines for CER. Yet in order for comparative effectiveness research to be a successful investment, new information on the clinical- and/or cost-effectiveness of a medical technology must be transmitted to physicians in ways that will effectively change practitioners' behavior enough that there is ultimately a change in their patients' outcomes.

To date there is limited evidence on the effectiveness of strategies that can be used to disseminate new information to practicing physicians. Physicians can obtain information from medical journals, schooling, or colleagues, but there are mixed results on what communication process has the greatest effect on physicians' clinical decisions. The best ways to communicate the effectiveness of new medical procedures, treatments and drugs to physicians are simply not well understood. In particular, a great deal of research has documented that there is a wide variation in the adoption of new technologies that is not explained by the characteristics of patients, hospitals, or physicians (Epstein \& Nicholson, 2009; Wennberg, 2002; Roos, 1984; Eisenberg \& Nicklin, 1981. When new medical technologies are introduced, physicians' adoption decisions are influenced by clinical trials, guidelines, recent literature, their own understanding of and experience with the new technology, uncertainty regarding the quality and effectiveness of the new technology, and whether the procedure is easily learned and compatible with existing practice (Escarce, 1996; Burke, Fournier, \& Prasad 2007). Physicians technology adoption decisions may also be influenced by hospital administrators and/or physicians who they interact with and provide feedback on the new technology.

New medical technologies, including new procedures, methods, prescription drugs, and equipment, develop at a rapid pace in the medical care market. An understanding of how to incentivize physicians to change their practice patterns in response to these new technologies doesn't only affect patient outcomes, it is also an important cost consideration for hospital administrators and insurance companies. Given the importance of understanding physicians' technological adoption decisions, this paper analyzes how physicians' social networks impact their use of a technology introduced for cardiac care, the drug-eluting stent. We study the rate of adoption of the drug-eluting stent by physicians from the time of its initial introduction in April of 2003 to the end of 2004 using data on all inpatients in Florida hospitals over this time period. After controlling for patient, hospital, physician, and local effects we determine how physicians' social networks impact the rate of adoption of the drug-eluting stents, under different specifications of physicians' social networks.

In the next section we provide background information on the drug-eluting stent, and then discuss previous literature on physician learning and the influence of social networks. The data are presented in Section II and the empirical model in Section IV. The last two sections discuss results and provide concluding remarks. 


\section{Background on Drug-Eluting Stents}

Drug-eluting stents (DES) are one type of treatment that is available to a cardiologist treating a patient with coronary artery disease. When a patient has a blocked or narrow coronary artery, the cardiologist may insert a small mesh tube, or stent, into the patient's arteries during a percutaneous transluminal coronary angioplasty (PTCA), a procedure that keeps the artery open by inserting and inflating a tiny balloon. The Food and Drug Administration (FDA) approved the use of drug-eluting stents in April of 2003. At that time the other treatments available for treating coronary artery disease were medical management and therapy, bare metal stents (BMS), and open heart bypass surgery. Bare metal stents, also small mesh tubes, were inserted into patients' arteries using the same methods and equipment that were eventually used for drug-eluting stents. The difference between bare metal stents and drug-eluting stents is that the latter have a polymer coating over the mesh that emits a drug over time that helps to prevent restenosis, which is a reoccurrence of the blockage. At the time the DES were introduced, between $10 \%$ and $20 \%$ of patients who received bare metal stents experienced restenosis, which required another percutaneous coronary intervention within six to 12 months after the BMS implantation. Two major trials had shown that DES reduced the rates of restenosis by $50-90 \%$ compared to BMS, although there were no differences in mortality, myocardial infarction rates, thrombosis, or other adverse events between patients receiving DES and those receiving BMS (Ryan \& Cohen, 2006; Shih \& Berliner, 2008).

DES were not designed to be a complete replacement of BMS. The FDA had created "on-label" use requirements for DES, which were clinical conditions under which a patient should receive a DES instead of a BMS. The DES were designed for patients who had the highest risk of restenosis, which is primarily patients with short lesions in a coronary artery and/or a coronary artery with a small diameter. After DES were proven to significantly reduce restenosis rates, many physicians saw DES as a method of treatment that not only reduced the need for repeat angioplasty procedures, which carry the risk of complications such as heart attack and stroke, but also prevented the need for more invasive procedures, such as coronary bypass surgery.

Drug-eluting stents are physician preference items, which means that ultimately the choice of treatment for the patient is made by the cardiologist responsible for the patient, not the hospital in which the patient is treated. Initially, the choice of DES was limited: the first drug-eluting stent was approved by the FDA in April 2003, and the second was approved in March 2004. Financial incentives affecting a cardiologist's decision to use DES or BMS differ from the financial incentives affecting the hospital in which the insertion procedure is performed. If the DES is successful at reducing patients' restenosis rates, hospitals (and physicians) will have their revenue reduced as a result of fewer repeated angioplasties and fewer CABG procedures. However, the initial cost of treatment for these patients is higher because the price of a DES is two to three times higher than the price of a conventional BMS (reference). This is a cost that is born by the hospital purchasing department, not the physician. 
The financial incentives that potentially influence cardiologists include the higher fee-for-service clinical payments for using DES instead of BMS, and greater payments for the use of multiple stents rather than a single stent (it is very common for a patient to receive more than one stent). Physicians may also receive consulting honoraria from device manufacturers to the extent they favor one brand of stent over another (Robinson and Nolan 2011). Also, since information on DES was widely available to the public via the internet, some physicians may choose to use drug-eluting stents to avoid a malpractice suit in the event that a patient who received a bare metal stent develops restenosis and argues they should have received a drug-eluting stent. Despite the high costs of using DES, their use is seen as highly cost-effective: Cutler (2007) estimates that the cost of angioplasty is about $\$ 33,000$ per year of extra life.

\section{Physicians' Learning and Adoption of New Technologies}

\subsection{Previous Literature}

One of the most prominent sources of physicians' learning that is commonly discussed in the literature is the use of clinical practice guidelines. According to the Institute of Medicine (1990), "Clinical practice guidelines are systematically developed statements to assist practitioner and patient about appropriate health care for specific clinical circumstances." For example, for cardiologists the guidelines may be developed by the American College of Physicians, the American College of Cardiology Foundation, and/or the American Heart Association. The guidelines are recommendations, not requirements, but they are typically based on evidence from a "rigorous systematic review and synthesis of the published medical literature" (reference) according to the National Center for Complementary and Integrative Health (NCCIH, 2017) (the NCCIH is part of the National Institutes of Health in the United States).

Many proponents of comparative effectiveness research claim that physicians can improve their patients' outcomes by referring to guidelines and other medical literature (e.g. medical journals) when they have questions about clinical diagnosis, prognosis, or management (Strauss \& McAlister, 2000). Certainly clinical guidelines play an important role in determining the proper treatment of patients, as they are taught by medical schools, used by insurance companies to determine reimbursement, and some federal pay-for-performance programs are making physicians' compensation contingent on following the recommendations embedded in the guidelines (Menchik \& Meltzer, 2010). Yet some authors have found that clinical practice guidelines have been "remarkably unsuccessful" in influencing physicians (Greco \& Eisenberg, 1993). Physicians are resistant to implement guidelines when the guidelines are based on clinical trials that result in uncertainly, or include a group of patients that are dissimilar to the physicians' own patients. Other authors have documented other barriers that undermine physicians' willingness and/or ability to adopt recommendations; such as physician attitudes including motivation, lack of agreement, self-efficacy, uncertainty regarding the quality and effectiveness of the new technology, and the inertia of previous practice (Escarce, 996; Burke, Fournier, \& Prasad, 2007).

Physicians' interpretations of the results of comparative effectiveness research will be 
influenced by the training they received in medical school, residency, and fellowship programs. Yet previous studies have found that even after controlling for physicians' training experiences, there is a still a great deal of unexplained variation in physicians' treatment decisions that reflect the variation in physicians' unobserved qualities, such as innate abilities, motivation, and efforts to assimilate new medical information (Grant \& McInnes, 2004; Epstein \& Nicholson 2009; Currie, MacLeod, \& Parys, 2016).

Physician leadership has been found to play a role in disseminating information on new technologies and effectively changing physicians' willingness to adopt new technologies. Burke, Fournier, and Prasad (2007, 2009) found that "star" physicians had a positive influence on the adoption of bare metal stents when they were introduced, where "star" physicians are those who completed a medical residency at a hospital ranked in the top 30 nationally. And while guidelines alone may not change physicians' practice patterns, providing guidelines to physician leaders, men and women named by their peers as trusted sources of clinical information, has shown success in altering physicians' practices (Lomas, Enkin, Anderson, Hannah, Vayda, \& Singer, 1991; Everitt, Soumerai, Avorn, Klapholz, \& Wessels, 1990). Some authors have found mixed results on the effectiveness of using a physician leader to implement change. Bradley et al. (2001) found that while higher-performing hospitals could use a physician leader to increase beta-blocker use, in lower-performing hospitals the effect of using a physician leader were described as weak or nonexistent.

Interviews with practicing physicians, as well as anecdotal evidence, indicate that many physicians rely primarily on their own experiences and judgement, and that of their colleagues, when deciding whether to adopt a new technology (Grego \& Eisenberg, 1993). Physicians interact with other physicians in regularly scheduled meetings, conferences, and informal exchanges of communication when treating patients in the same facility (Rogers 1995; Valente 1996; Kuo, Gifford, \& Stein 1998). Formal and informal communication between physicians may lead to advice seeking and learning of new interventions to use with patients (Anspach, 1993; Jin, 2005).

\subsection{Measuring Physicians' Networks}

Measuring physicians' social networks has taken several forms. Barnett et al. (2012) use a shared patient approach to determine the number of connections held by each physician. They determined that hospitals with doctors who have higher number of connections have higher costs and more intensive care. Pollack, Weissman, Bekelman, Liao and Armstrong (2012) also constructed physician social networks based on shared patients, and found that for patients with prostrate cancer, treatments vary based on physician network effects after adjusting for patient clinical and demographic characteristics.

The validity of using administrative data to model physician networks was tested in Barnett et al. (2011), who compared physician networks created from Medicare administrative data to results from a survey examining professional relationships among physicians. Their results supported the hypothesis that patient-sharing, as observed in administrative data, is a valid method for identifying relationships between physicians. Also, Barnett et al. (2011) found 
that "there was no clinically significant difference in the proportion of relationships recognized within an academic medical center when physicians share zero patients or one patient during the course of year..." (p. 1605). This result suggests that if physician networks are created such that two physicians are only required to share one patient in order to have a social connection, or physician-to-physician tie, this may result in a weak measure of physician networks. In our empirical model we use two variations of the measures of physician networks: networks where a tie between two physicians exists when they have shared one or more patients, and networks where a tie between two physicians exists when they have shared two or more patients.

\section{Data}

\subsection{Sources and the Sample}

Our model examines how physicians' social networks affect physicians' adoption of a new technology, the drug-eluting stent. We choose this technology because adopting the drug-eluting stent did not require an investment in new infrastructure or equipment, and the procedural method required to use DES was so similar to the procedural method of the existing technology (BMS) that any investment by the physician in learning the procedure would be minimal. Using data on all inpatients in Florida hospitals from the time of the initial introduction of drug-eluting stents in April 2003 to the end of 2004, we analyze how physicians' social networks are related to the rate of adoption of the DES after controlling for patient, hospital, physician, and local effects. Patient data are available from the Florida Agency for Health Care Administration (FLAHCA), and include demographic information on the inpatients, as well as insurance status, diagnosis and procedures codes, an identifier for the patient's hospital, and identifiers for up to two physicians. Data on hospitals are also available from the FLAHCA. The Medical Quality Assurance division of the Florida Department of Health provided physician data.

\subsubsection{Sample}

Patients are included in our sample if they are 25 years old or older and did not receive a coronary bypass graft during the same hospital admission in which they received an angioplasty. Of the 135,500 patients, 25 and older, who received angioplasties in 2003 or 2004, 66,421 (49.0\%) received at least one drug-eluting stent, 46,231 (34.1\%) received at least one bare-metal stent, 3,907 (2.9\%) received both a bare-metal and a drug-eluting stent, and 18,491 (13.6\%) did not receive either type of stent. Patients are only included in our sample if they receive an angioplasty (PTCA) and either a BMS or DES. Since we wish to analyze physicians' adoption rate of DES, we only include patients for whom the physician has determined that a stent is appropriate. After dropping the patients who did not receive a stent, we merged the 117,009 remaining patients with the hospital data. Five patients did not have a hospital identifier that allowed us to determine the patient's hospital, and these five observations had to be dropped. Next, 37 patients had to be dropped because their physician's identifier was recorded incorrectly (e.g. "9999" or "8888"), and 4 patients were dropped because their physician's identifier indicated they were treated by a nurse. Finally, 12 patients were dropped because the hospital in which they were treated did not have a cardiac 
catheterization laboratory or coronary care unit, where these procedures should be performed.

\subsubsection{Descriptive Statistics of Patient and Hospital Characteristics}

Florida is divided into 11 health council districts by state officials for the purposes of health planning. We treat each health council district as the region in which a physician forms his/her social network. Descriptive statistics on many of the patient and hospital characteristics for five of the eleven health council districts are shown in Table 1. These five districts are the two smallest (with the fewest inpatients), the two largest, and the median district, based on total patients. The mean values for patient characteristics that are shown in Table 1 are computed by averaging the characteristic across all patients in a particular health council district for the entire time period of the analysis, the second quarter of 2003 to December of 2004. As shown in Table 1., more patients are seen in some health council districts than others, as the number of patients within a health council district who received a stent over this time period ranges from a low of 3,410 in health council district 2 to a high of 16,490 patients in health council district 7 . The mean values of patients' age and the percent of patients who are female are quite similar across the health council districts. We expect a physician's percent of patients who receive a drug-eluting stent to be higher for physicians who treat younger patients, patients with fewer acute myocardial infarctions (heart attacks), more patients who receive a multi-vessel PTCA, and/or patients who have a higher ICISS survival probability (for a full explanation of the ICISS survival probability, please see Appendix 1 at the end of this document). For physicians who treat more uninsured and/or Medicaid patients, we expect the percent of the physicians' patients who receive drug-eluting stents to be lower.

The bottom half of Table 1 shows the mean values for hospital characteristics, where the means are specific to the hospitals within a particular district. There are between 4 and 18 hospitals in each health council district that have a coronary care unit and/or a cardiac catheterization laboratory. Each hospital is classified into one of three categories of ownership: not-for-profit, investor-owned, or government hospital. A hospital's ownership type may influence whether and how hospital administrators attempt to influence physicians' use of a new, more expensive medical technology. The teaching indicator is equal to one if the hospital has a residency program in cardiology. Cardiologists in a teaching hospital may devote more time and effort to learning about a new technology and to researching the effectiveness of the new technology relative to the existing technologies available. The drug-eluting stents may be adopted more rapidly in a teaching hospital if the cardiologists are paying more attention to newly introduced technologies than the general population of cardiologists. However, on the other hand, physicians in a teaching hospital may use more discretion in adopting the technology by ensuring that the DES are only given to patients according to the guidelines, rather than as a complete replacement of bare metal stents. Given the conflicting effects of these two possibilities on physicians' adoption of DES, we are unsure how physicians' use of DES may differ for physicians in a teaching hospital, a priori. 
Table 1. Descriptive Statistics on Patients and Hospitals in Select Health Council Districts in Florida, 2003 - 2004

\begin{tabular}{|c|c|c|c|c|c|}
\hline & \multicolumn{5}{|c|}{ Florida Local Health Council Districts } \\
\hline & 1 & 2 & 3 & 5 & 7 \\
\hline \multicolumn{6}{|l|}{ Patient Level Characteristics } \\
\hline Number of patients & 4,122 & 3,410 & 9,225 & 11,475 & 16,490 \\
\hline Patient Age & 64.3 & 63.0 & 66.8 & 67.4 & 65.4 \\
\hline Female $(\%)$ & 32.3 & 36.0 & 35.1 & 36.7 & 34.2 \\
\hline African-American (\%) & 6.4 & 10.6 & 4.3 & 2.4 & 5.4 \\
\hline Hispanic $(\%)$ & 0.5 & 0.8 & 1.7 & 1.8 & 7.7 \\
\hline Acute Myocardial Farction (AMI) & 32.1 & 25.6 & 27.5 & 25.2 & 25.4 \\
\hline Multi-Vessel PTCA (\%) & 17.0 & 12.2 & 17.0 & 23.0 & 25.7 \\
\hline ICISS Survival Probability & 82.6 & 84.6 & 83.7 & 83.7 & 84.2 \\
\hline Uninsured (\%) & 4.9 & 5.7 & 4.8 & 4.3 & 4.4 \\
\hline Medicaid (\%) & 3.5 & 3.9 & 3.3 & 2.3 & 2.5 \\
\hline Medicare (\%) & 56.2 & 51.5 & 66.8 & 64.0 & 57.3 \\
\hline Privately Insured (\%) & 27.9 & 34.6 & 23.4 & 26.6 & 33.7 \\
\hline \multicolumn{6}{|l|}{ Hospital Characteristics } \\
\hline Number of Hospitals & 6 & 4 & 8 & 9 & 18 \\
\hline Not-for-Profit: \# of Hospitals & 3 & 1 & 6 & 4 & 15 \\
\hline Not-for-Profit: $\%$ of Patients & 53.3 & 38.0 & 73.1 & 47.1 & 92.7 \\
\hline Government: \# of Hospitals & 0 & 1 & 0 & 0 & 1 \\
\hline Government : $\%$ of Patients & 0 & 47.2 & 0 & 0 & 0 \\
\hline Investor Owned: \# of Hospitals & 3 & 2 & 2 & 5 & 2 \\
\hline Investor Owned: $\%$ of Patients & 46.7 & 14.8 & 26.9 & 52.9 & 7.3 \\
\hline Teaching: \# of Hospitals & 0 & 0 & 2 & 0 & 5 \\
\hline Teaching: $\%$ of Patients & 0 & 0 & 16.2 & 0 & 18.9 \\
\hline $\begin{array}{l}\text { Number of Beds for Acute/Intensive } \\
\text { Care: Hospital Level }\end{array}$ & 315 & 354 & 365 & 340 & 357 \\
\hline $\begin{array}{l}\text { Number of Beds for Acute/Intensive } \\
\text { Care: Patient Level }\end{array}$ & 418 & 471 & 378 & 445 & 1,210 \\
\hline $\begin{array}{l}\text { Cardiac Full Time Equivalent Nurses: } \\
\text { Hospital Level }\end{array}$ & 58.0 & 125.5 & 158.6 & 103.6 & 432.6 \\
\hline
\end{tabular}


Cardiac Full Time Equivalent Nurses:

Patient Level

$77.7 \quad 150.6$

217.0

59.0

464.0

Mean of Counties' Median Income:

Patient Level

$\$ 38,313 \quad \$ 38,617 \quad \$ 35,317 \quad \$ 37,380 \quad \$ 42,195$

In Table 1 we show the averages for hospital characteristics at the hospital level and the patient level for clarity. For example, we show the number of hospitals of each ownership category within a health council district, and the percent of patients seen in that ownership type of hospital in order to show where patients are being treated. For example, in district 2, the one not-for-profit hospital represents $25 \%$ of all hospitals in the district, but $38 \%$ of the patients in the district were seen in this hospital. Also, in district 2, the mean number of beds across the four hospitals is 354 beds. However, when the number of beds within the four hospitals is averaged across all the patients seen in the four hospitals, the average beds is 471 , indicating that many patients are being treated in the hospitals with more beds than the average of 354 .

The eleven health council districts in Florida have one to sixteen exclusive counties, where district 10 is the sole district with only one county, Broward County, which houses the Miami metropolitan area. Using the patient-level data, we averaged the counties' median income across patients for each health council district.

\subsection{Physicians'Social Networks and other Characteristics}

\subsubsection{Physicians' Social Networks}

Based on this data we treat the network formation as occurring within a health council district for each physician. Therefore, a physician's social network is based on shared patients with other physicians in hospitals in a particular health council district. Physicians can provide an angioplasty to a patient with or without the assistance of a second physician, so some patients are treated by only one physician.

We construct physician networks based on shared patients using the administrative data on inpatients in Florida hospitals. As mentioned previously, for each patient in our data, a physician identifier is recorded for up to two physicians treating the patient. A physician has a tie with another physician if they are both recorded as having treated the patient in the inpatient data. From this data we can determine the number of shared patients between two physicians in a given time period. Since the hospital inpatient data is provided on a quarterly basis, each time period is a quarter from the second quarter of April 2003 to the last quarter in December 2004, for a total of seven quarters of data.

We use two measures of physicians' social networks that have been frequently used in previous literature to model physician networks. The first is degree centrality, which refers to the number of other physicians a particular physician has ties to, as a percentage of all possible ties. A physician who has ties to more physicians than another physician may have 
multiple alternative ways to learn information about the new procedure and more opportunities to be persuaded to use it. In our empirical model we use adjusted degree centrality, which weights each physician-to-physician tie by the number of shared patients between the two physicians. The second measure of a physician's social network is between centrality, which measures the number of times a physician lies on the shortest path between other physicians; it indicates which physicians act as a bridge between other physicians. A physician with high between centrality controls information passing between other physicians. Only one measure of physicians' networks are included in each empirical estimation; we test the model with both measures of social networks because a physician can have low degree centrality, and be connected to other physicians with low degree centrality, but still have high betweenness centrality because the physician frequently lies on a path between other physicians in the health council district. For both measures, degree centrality and between centrality, the higher values of the measures represent more expansive physician networks. For the few physicians who are not observed to work with any other physicians throughout the entire time period, the social network work measures are set to zero.

Figure 1 shows trends in the use of drug-eluting stents over our sample time period, the second quarter in 2003 to the fourth quarter of 2004. To construct this graph, we divided physicians into thirds based on degree centrality. Those physicians who had values of degree centrality in the lowest third ( $33^{\text {rd }}$ percentile and lower) have the "smallest networks" and those physicians who had the highest values of degree centrality $\left(66^{\text {nd }}\right.$ percentile and higher) have the "largest networks." The adjusted rate of drug-eluting stent is constructed using patient-level data. This is the standardized rate of patients receiving a drug-eluting stent instead of a bare-metal stent, adjusted for the patient's age, gender, race, presence of an AMI, and whether the patients received treatment on multiple heart vessels. After calculating the rate using patient-level data, we find the averages for the three separate categories of degree centrality. Over this time period all three groups of physicians rapidly adopted the drug-eluting stent, but this figure suggests that physicians with the smallest networks tended to utilize drug-eluting stents at a lower rate than physicians with larger networks over this time period. 


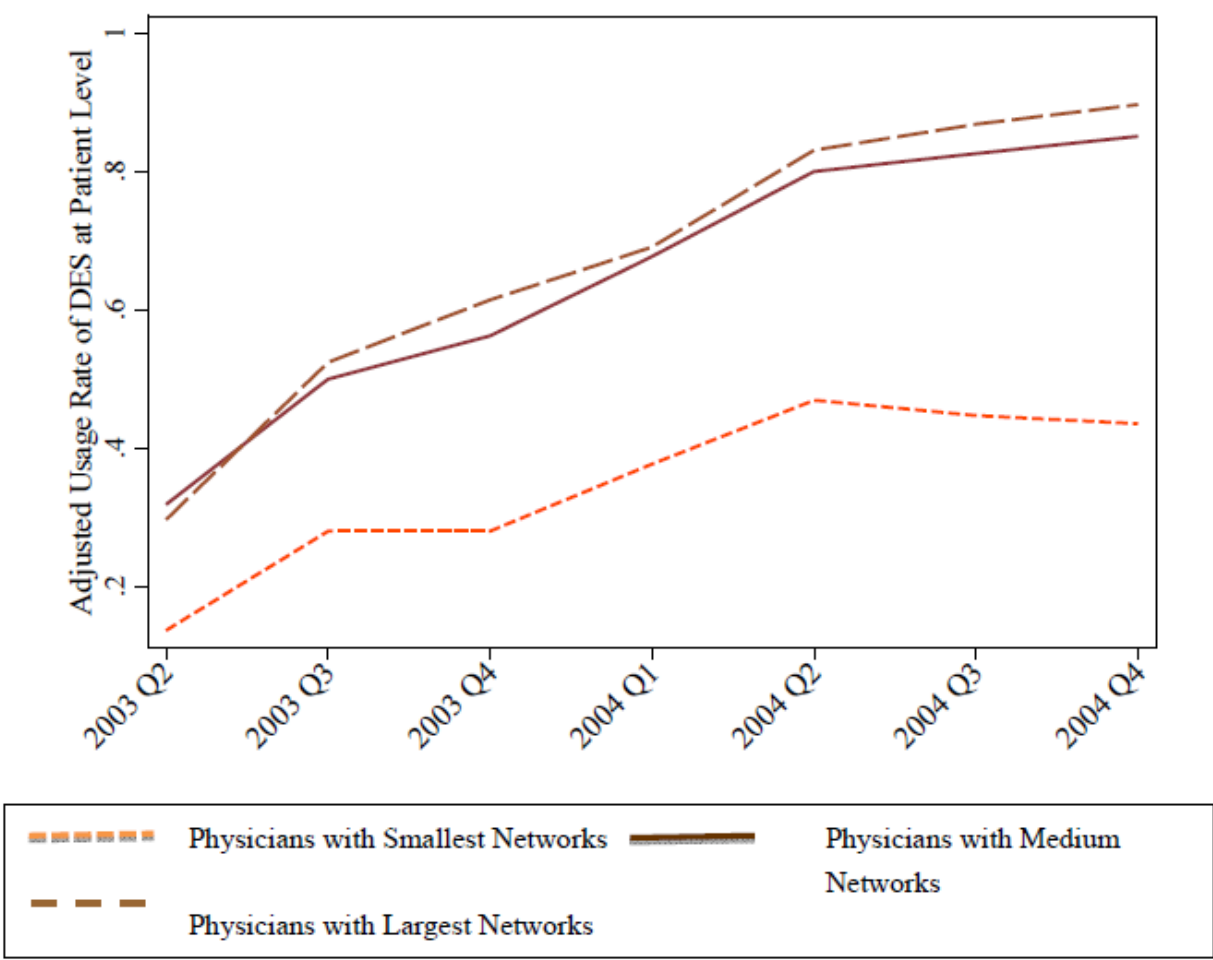

Figure 1. Patients' Adjusted rate of receiving drug-eluting stents instead of bare-metal stents, by physician networks

Physician-specific characteristics are shown in Table 2. During this time period there was a wide range in the number of cardiologists within a health council district, from a low of 43 in district 2 to a high of 220 in district 7. The 'Number of physician-physician ties' is the number of ties between two physicians in each health council district, over the entire time period, where a tie exists if the operating physician works with a different physician (the attending physician) when providing a stent to a patient. For this table, these ties only require that the two physicians work together to treat, or "share" one patient. The mean number of shared patients per physician is only based on patients that are treated by two physicians; it does not include values of zero for those physicians who work on a patient alone.

\subsubsection{Other Physician Characteristics}

In addition to the measures of physicians' networks, we include indicators of the physicians' training that are non-time varying and are designed to capture the quality of the physicians' training. For these indicators, physicians are divided into three categories: physicians who are from one of the top 30 ranked medical schools and/or residency programs, physicians who are board certified in cardiology but not from a top ranked medical school or residency program, and physicians who are neither board certified in cardiology nor from a top ranked program (this is the base category). Data on the annual rankings of medical schools and rankings of U.S. Heart Hospitals (in which residents complete their residencies) are available from the U.S. News \& World Report (2006a and 2006b, respectively). 


\section{Ml Macrothink}

The choice of stent to be given to a patient is a physician preference item. We include these measures of physicians' training because these measures may capture a physician's ability and/or willingness to learn about the comparative effectiveness of the new technology, and/or their confidence in using the new technology. Previous studies have found that physicians' training (Lichtenberg 2009; Currie et al. 2016) and board certification (Freiman 1985; Escarce 1996) are related physicians' use of medical technologies and/or patients' outcomes. We expect physicians who are trained in top residencies and medical schools to adopt the DES more rapidly than those who are neither board certified nor trained in a top-ranked program. The percent of physicians who fall into each of these categories, in the five health districts, is shown in the bottom of Table 2.

\section{Empirical Model}

To estimate the physicians' adoption rate of DES, we use as the dependent variable the percent of a physician's patients who received a drug-eluting stent, out of all the physician's patients who received a bare-metal or drug-eluting stent in a given quarter and health council district:

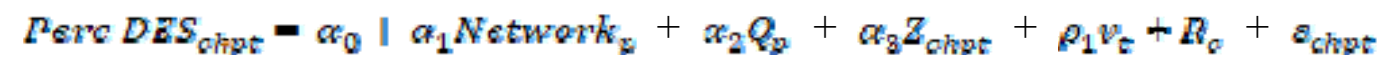

where Perc DES $S_{\text {chpt }}$ is the percent of patients seeing physician $p$ in health council district $c$ and hospital $h$ who received a drug-eluting stent at time $t$. The observation level in the empirical model is a physician in health council district $c$ in quarter (and year) $t$. For the dependent variable, the numerator is the number of the physicians' patients who received a drug-eluting stent from the physician in a particular health council district (and quarter). The denominator is the total number of patients who received either a bare metal or drug-eluting stent from the physician in a particular health council district and quarter. Using the inpatient-level data, we aggregate the data to the physician level and use averages of the patient and hospital characteristics for a particular physician, in a particular quarter, as right-hand side variables in the model.

Table 2. Physician Characteristics in Select Health Council Districts in Florida, 2003 - 2004

\begin{tabular}{|c|c|c|c|c|c|}
\hline & \multicolumn{5}{|c|}{ Florida Local Health Council Districts } \\
\hline & 1 & 2 & 3 & 5 & 7 \\
\hline Number of unique operating physicians & 46 & 43 & 77 & 136 & 220 \\
\hline Number of physician to physician ties ${ }^{\mathrm{a}}$ & 553 & 459 & 1,462 & 1,810 & 2,949 \\
\hline Mean number of shared patients per physician ${ }^{b}$ & 42.6 & 35.4 & 64.3 & 28.2 & 33.9 \\
\hline Mean Degree Centrality for Operating Physicians & 33.2 & 40.4 & 18.9 & 7.9 & 2.8 \\
\hline Mean Between Centrality for Operating Physicians & 4.4 & 1.7 & 4.2 & 1.8 & 1.1 \\
\hline Mean Percent of Physician's Patients Receiving & 62.1 & 57.9 & 57.1 & 63.6 & 80.0 \\
\hline
\end{tabular}


Drug-Eluting Stents ${ }^{\mathrm{c}}$

Physician Training Characteristics

Percent Not Board Cert. or from Top Ranked

Medical School or Residency

$\begin{array}{lllll}27.3 & 20.0 & 17.2 & 18.0 & 13.6\end{array}$

Percent Board Cert. but Not Top Ranked Medical

School or Residency

$\begin{array}{lllll}36.4 & 43.3 & 50.0 & 55.1 & 53.7\end{array}$

Percent from Top Ranked Medical School or Residency

$\begin{array}{lllll}36.4 & 36.7 & 32.8 & 27.0 & 32.7\end{array}$

a A tie occurs between two physicians when they both treat one patient during an angioplasty procedure.

b This does include those physicians who only work alone, and have no shared patients. Those physicians will be included in the empirical results.

${ }^{c}$ This mean is weighted by the number of patients seen by a physician in the health council district.

As mentioned in section 4.2.1, two specifications of the physicians' networks, Network, will be explored: degree centrality and between centrality. The three indicators of the physicians' training that were described in the previous section are included in $Q_{p}$; these are non-time varying and are designed to capture the quality of the physicians' training.

Averages of patients' characteristics, hospitals' characteristics, and characteristics of the health council district for physician $p$ in district $c$ at time $t$ are represented by $Z_{c h p t}$. This vector includes mean values of the patients' characteristics, such as mean age or the percent uninsured, mean values of the hospitals where the patients are seen by physician $p$ in district $c$, such as the percent of physicians' patients seen in hospitals that are not-for-profit, and the mean income of counties in district $c$. The average for the right-hand side characteristics $Z_{c h p t}$ will differ from those shown in Table 1, because they are specific to the physician and the physicians' patients at time $t$. For example, the mean value for 'Not-for-profit' in $Z_{\text {chpt }}$ is based on where physician $p$ treated patients at time $t$. If a physician treated all his/her patients in one hospital, then the mean value for 'Not-for-Profit' is based on the ownership of that one hospital. If a physician treated patients in more than one hospital in the health council district, the mean value of 'Not-for-profit' is based on the number of patients seen in each hospital, and the ownership type of each hospital, since the mean value is the average across all of the physicians' patients at time $t$.

We also include time indicators for each quarter, $v_{t}$. There are seven quarters in the data, from the second quarter of 2003 through the last quarter of 2004. The time indicators will capture trends that occurred over time across the state of Florida, such as policy changes or changes in the state economy. The base category is the first quarter the drug-eluting stents were FDA-approved, the second quarter in 2003.

Indicators for ten of the eleven health council districts are also included in the empirical model. These indicators will capture unobserved characteristics of each health council district 
that are constant over time, such as opportunities for physicians to network, or environmental health in the area (e.g. air quality).

This model is fit using generalized linear modeling with maximum likelihood (Newton-Raphsom) optimization, where the dependent variable has a binomial distribution and a probit link. All models are estimated using Stata 15.1.

\section{Results}

Results from estimating the equation in section 5. are shown in Table 3, where there are four specifications of the model based on the following: using degree centrality or between representing physicians' training. We estimated the model separately without the indicators centrality to represent physicians' networks, and including or not including the indicators for physicians' training because for many physicians in our sample, this data is unavailable, as seen by the number of observations at the bottom of Table 3 .

Table 3. Results from Social Network Specification Based on One Shared Patient

\begin{tabular}{|c|c|c|c|c|}
\hline & \multicolumn{2}{|c|}{$\begin{array}{l}\text { With Physician } \\
\text { Measures }\end{array}$} & \multicolumn{2}{|c|}{$\begin{array}{l}\text { Without Physician Training } \\
\text { Measures }\end{array}$} \\
\hline Degree Centrality & $\begin{array}{l}0.383 \\
(0.076)^{* * *}\end{array}$ & & $\begin{array}{l}0.442 \\
(0.064) * * *\end{array}$ & \\
\hline Between Centrality & & $\begin{array}{l}1.191 \\
(0.309)^{* * *}\end{array}$ & & $\begin{array}{l}1.201 \\
(0.277)^{* * *}\end{array}$ \\
\hline Board Certified & $-0.025(0.050)$ & $-0.026(0.050)$ & & \\
\hline Top Ranked & $\begin{array}{l}-0.145 \\
(0.053)^{* *}\end{array}$ & $\begin{array}{l}-0.144 \\
(0.053) * * *\end{array}$ & & \\
\hline $\begin{array}{l}\text { Means of Patient } \\
\text { Characteristics }\end{array}$ & & & & \\
\hline African-American & $\begin{array}{l}-0.220 \\
(0.129)^{*}\end{array}$ & $\begin{array}{l}-0.227 \\
(0.128)^{*}\end{array}$ & $\begin{array}{l}-0.194 \\
(0.103)^{*}\end{array}$ & $\begin{array}{l}-0.202 \\
(0.103)^{* *}\end{array}$ \\
\hline AMI & $-0.091(0.075)$ & $-0.091(0.075)$ & $\begin{array}{l}-0.103 \\
(0.062)^{*}\end{array}$ & $\begin{array}{l}-0.102 \\
(0.062)^{*}\end{array}$ \\
\hline Multi-Vessel PTCA & $\begin{array}{l}0.343 \\
(0.094)^{* * *}\end{array}$ & $\begin{array}{l}0.347 \\
(0.094)^{* * *}\end{array}$ & $\begin{array}{l}0.323 \\
(0.075)^{* * *}\end{array}$ & $\begin{array}{l}0.327 \\
(0.075)^{* * * *}\end{array}$ \\
\hline $\begin{array}{l}\text { ICISS } \\
\text { Probability }\end{array}$ & $\begin{array}{l}0.769 \\
(0.237)^{* * *}\end{array}$ & $\begin{array}{l}0.775 \\
(0.238)^{* * *}\end{array}$ & $\begin{array}{l}0.610 \\
(0.198)^{* * *}\end{array}$ & $\begin{array}{l}0.625 \\
(0.199) * * *\end{array}$ \\
\hline Uninsured & $\begin{array}{l}-0.004 \\
(0.002)^{* * *}\end{array}$ & $\begin{array}{l}-0.004 \\
(0.002)^{* * *}\end{array}$ & $-0.002(0.001)$ & $\begin{array}{l}-0.002 \\
(0.001)^{* * *}\end{array}$ \\
\hline Medicaid & -0.006 & -0.006 & -0.004 & -0.004 \\
\hline
\end{tabular}




\section{Macrothink Institute}

\begin{tabular}{|c|c|c|c|c|}
\hline & $(0.002)^{* * *}$ & $(0.002)^{* * *}$ & $(0.001)^{* * *}$ & $(0.001)^{* * *}$ \\
\hline Commercial Insurance & $-0.000(0.001)$ & $-0.000(0.001)$ & $0.001(0.001)$ & $0.000(0.001)$ \\
\hline $\begin{array}{l}\text { Means of Hospital } \\
\text { Characteristics }\end{array}$ & & & & \\
\hline Hospital Beds & $\begin{array}{l}0.004 \\
(0.001)^{* * *}\end{array}$ & $\begin{array}{l}0.004 \\
(0.001)^{* * *}\end{array}$ & $\begin{array}{l}0.003 \\
(0.001)^{* * *}\end{array}$ & $\begin{array}{l}0.003 \\
(0.001)^{* * *}\end{array}$ \\
\hline Cardiac FTE Nurses & $0.002(0.001)$ & $\begin{array}{l}0.002 \\
(0.001)^{*}\end{array}$ & $\begin{array}{l}0.003 \\
(0.001)^{* *}\end{array}$ & $\begin{array}{l}0.003 \\
(0.001)^{* * *}\end{array}$ \\
\hline Not-for-Profit & $\begin{array}{l}0.417 \\
(0.067)^{* * *}\end{array}$ & $\begin{array}{l}0.418 \\
(0.067)^{* * *}\end{array}$ & $\begin{array}{l}0.433 \\
(0.055)^{* * *}\end{array}$ & $\begin{array}{l}0.427 \\
(0.055)^{* * *}\end{array}$ \\
\hline Investor-Owned & $\begin{array}{l}0.246 \\
(0.072)^{* * *}\end{array}$ & $\begin{array}{l}0.268 \\
(0.072)^{* * *}\end{array}$ & $\begin{array}{l}0.265 \\
(0.059)^{* * *}\end{array}$ & $\begin{array}{l}0.277 \\
(0.060)^{* * *}\end{array}$ \\
\hline Teaching & $\begin{array}{l}0.173 \\
(0.063)^{* * *}\end{array}$ & $\begin{array}{l}0.157 \\
(0.062)^{* * *}\end{array}$ & $0.058(0.051)$ & $0.038(0.051)$ \\
\hline Counties' Median Income & $\begin{array}{l}0.469 \\
(0.284)^{*}\end{array}$ & $\begin{array}{l}0.549 \\
(0.283)^{* *}\end{array}$ & $\begin{array}{l}0.416 \\
(0.234)^{*}\end{array}$ & $\begin{array}{l}0.505 \\
(0.234)^{* *}\end{array}$ \\
\hline $2003, Q=3$ & $\begin{array}{l}0.618 \\
(0.053)^{* * *}\end{array}$ & $\begin{array}{l}0.618 \\
(0.053)^{* * *}\end{array}$ & $\begin{array}{l}0.631 \\
(0.043)^{* * *}\end{array}$ & $\begin{array}{l}0.631 \\
(0.043)^{* * *}\end{array}$ \\
\hline 2003, $Q=4$ & $\begin{array}{l}0.744 \\
(0.054)^{* * *}\end{array}$ & $\begin{array}{l}0.741 \\
(0.054)^{* * *}\end{array}$ & $\begin{array}{l}0.772 \\
(0.044)^{* * *}\end{array}$ & $\begin{array}{l}0.768 \\
(0.044)^{* * *}\end{array}$ \\
\hline 2004, $Q=1$ & $\begin{array}{l}0.950 \\
(0.056)^{* * *}\end{array}$ & $\begin{array}{l}0.947 \\
(0.056)^{* * *}\end{array}$ & $\begin{array}{l}0.983 \\
(0.046)^{* * *}\end{array}$ & $\begin{array}{l}0.980 \\
(0.046)^{* * *}\end{array}$ \\
\hline $2004, Q=2$ & $\begin{array}{l}1.472 \\
(0.060)^{* * *}\end{array}$ & $\begin{array}{l}1.466 \\
(0.059)^{* * *}\end{array}$ & $\begin{array}{l}1.514 \\
(0.049)^{* * *}\end{array}$ & $\begin{array}{l}1.509 \\
(0.049)^{* * *}\end{array}$ \\
\hline $2004, Q=3$ & $\begin{array}{l}1.653 \\
(0.061)^{* * *}\end{array}$ & $\begin{array}{l}1.649 \\
(0.061)^{* * *}\end{array}$ & $\begin{array}{l}1.694 \\
(0.051)^{* * *}\end{array}$ & $\begin{array}{l}1.689 \\
(0.051)^{* * *}\end{array}$ \\
\hline $2004, Q=4$ & $\begin{array}{l}1.753 \\
(0.064)^{* * *}\end{array}$ & $\begin{array}{l}1.751 \\
(0.064)^{* * *}\end{array}$ & $\begin{array}{l}1.752 \\
(0.053)^{* * *}\end{array}$ & $\begin{array}{l}1.749 \\
(0.053)^{* * *}\end{array}$ \\
\hline Constant & $\begin{array}{l}-7.004 \\
(3.03)^{* *}\end{array}$ & $\begin{array}{l}-7.739 \\
(3.02)^{* * *}\end{array}$ & $\begin{array}{l}-6.607 \\
(2.49)^{* * *}\end{array}$ & $\begin{array}{l}-7.404 \\
(2.49)^{* * *}\end{array}$ \\
\hline Log pseudolikelihood & $-1,724.8$ & $-1,727.2$ & $-2,549.0$ & $-2,554.9$ \\
\hline Number of observations & 3,948 & 3,948 & 5,822 & 5,822 \\
\hline
\end{tabular}

Issues in Economics and Business

ISSN 2377-2301 2020, Vol. 6, No. 1 
together. In Table 4 we present results from estimating the model when the network measures are created with the requirement that a physician-to-physician tie only exists if the two physicians worked on two or more patients, following the recommendation in Barnett et al. (2012). For the results shown in Tables 3 and 4, the two network measures are based on the entire time period, so that the network measure for a particular physician is constant over time. This is done because the frequency with which physicians work with other physicians on angioplasty patients may vary over the year, yet physicians may have frequent contact with the physicians they work with at some time or another. Thus, making the physician's network time specific would make the physician networks appear to be much more variable than they truly are to the physicians. Results for the models shown in Tables 3 and 4 also include indicators for ten of the eleven health council districts, and are estimated with robust standard errors.

The results in Table 3 indicate that there are statistically significant and positive relationships between the extensiveness of physicians' networks and the percent of physicians' patients who received the new medical technology. The coefficients on both degree centrality and betweenness centrality are positive and statistically significant at the one percent or five percent level in all specifications. The quantitative effects of the network measures on the percent of physicians' patients receiving DES are slightly smaller when the physicians' training indicators are included and the sample size is smaller.

The percent of a physician's patients who receive drug-eluting stents does not significantly differ between board certified physicians and those who are not board certified. However, physicians who are from top ranked schools and/or programs give drug-eluting stents to a smaller percentage of patients than those physicians who had less prestigious training. This is probably because physicians from top programs use more discretion in determining whether a patient has the FDA-approved conditions that warrant the 'on-label' use of drug-eluting stents instead of bare-metal stents, whereas physicians who are not yet board certified or from top programs may simply use the drug-eluting stents on nearly all patients. The results hold even after controlling for the percent of patients the physician treats in a teaching hospital, shown towards the bottom of the table. Relative to non-teaching hospitals, physicians who treat more patients in a teaching hospital give a greater percentage of patients the drug-eluting stent instead of the bare metal stent. Sometimes patients with more complicated conditions are sent to teaching hospitals, so it could be that these patients had complicated conditions that were not captured by the measures of patients' health.

As for patient characteristics, we included all of the right-hand side variables shown in Table 3 , as well as indicators for each of the 30 comorbidities included in the Elixhauser comorbidity index and the percent of the physicians' patients who are Hispanic at time $t$. The results in Table 3 indicate that physicians who give a higher percentage of their patients the drug-eluting stents are those physicians whose patients have a higher ICISS survival probability, more patients who receive a multi-vessel angioplasty, fewer patients who have an AMI, and fewer patients who are uninsured or on Medicaid. As for the hospital characteristics, a greater share of physicians' patients will receive a drug-eluting stent if they are in larger hospitals (with more beds), and/or not-for-profit or investor-owned hospitals instead of 
government-owned hospitals.

In another specification, not shown in Table 3, we allowed some updating of a physician's network by making the network measures year specific, so that the value of a physician's network in the three quarters in 2003 is different from the value of the physician's network in 2004. This specification allowed some updating yet should capture the average extensiveness of a physician's network. In the results for that specification, the quantitative size of the coefficients, and their statistical significance, were very similar to the results shown in Tables 3 and 4 . Results are available from the authors upon request.

In Table 4 the estimated models are the same as those in Table 3, except that when the physician network measures are created, we impose the restriction that the physician-to-physician tie only exists if the two physicians treat two or more angioplasty patients together (whereas a physician-to-physician tie only required one or more shared patients for the social network measures in Table 3). There are some physicians who never share more than one patient with any other physicians; for these physicians the social network measures are set to values of zero (the social network measures are also set to values of zero if the physician never worked with other physicians over this time period). Even with the requirement that a social network develops only if physicians share two or more patients, the coefficients on the social network measures in Table 4 are the same, in sign and statistical significance, as the coefficients in Table 3 . The coefficient results are also very similar for the patient and hospital characteristics, as well. Notably, in all models there is a strong time trend in the use of drug-eluting stents, as physicians gave drug-eluting stents to a greater share of their patients over time.

\section{Concluding Discussion}

When new medical technologies become available that could effectively change physician behavior in a way that is beneficial for patients' outcomes, it is important for information about the new technology to be communicated to physicians in a way that allows them to easily learn evidence-based clinical information, understand how it fits within their current practice, and have practical methods and tools that allow physicians to effectively implement changes to their practice.

Physicians' decisions influence not only the health of their patients but also the cost of their care. The ability to change physicians' practices could improve the quality of health care while controlling expenditures. The purpose of this study was to determine whether physicians' networks affected their use of a new medical technology, the drug-eluting stents. Using different measures of physicians' social networks and controlling for physician, patient, hospital, and local characteristics, our results indicate that physicians who have broader networks, either because they work with more physicians in their field and/or because they are more often a bridge between other physicians, use a new medical technology more frequently than physicians with less extensive networks. In future work, researchers should consider more methods for measuring physicians' networks and examine the effects of physicians' networks on the use of other medical technologies. Our results indicate that hospital administrators, insurance companies, and policy makers who seek to influence 
physician behavior should consider that physicians may be strongly influenced by their social networks with other physicians.

Table 4. Results from Model Specification B.: Two Shared Patients

\begin{tabular}{|c|c|c|c|c|}
\hline & \multicolumn{2}{|c|}{$\begin{array}{l}\text { With Physician Training } \\
\text { Measures }\end{array}$} & \multicolumn{2}{|c|}{$\begin{array}{l}\text { Without Physician Training } \\
\text { Measures }\end{array}$} \\
\hline Degree Centrality & $\begin{array}{l}0.177 \\
(0.046)^{* * *}\end{array}$ & & $\begin{array}{l}0.213 \\
(0.038) * * *\end{array}$ & \\
\hline Between Centrality & & $\begin{array}{l}0.599 \\
(0.302)^{* *}\end{array}$ & & $\begin{array}{l}0.682 \\
(0.244)^{* * *}\end{array}$ \\
\hline Board Certified & $-0.027(0.050)$ & $-0.031(0.050)$ & & \\
\hline Top Ranked & $\begin{array}{l}-0.148 \\
(0.053)^{* * *}\end{array}$ & $\begin{array}{l}-0.149 \\
(0.053)^{* * *}\end{array}$ & & \\
\hline $\begin{array}{l}\text { Means of Patient } \\
\text { Characteristics }\end{array}$ & & & & \\
\hline African-American & $\begin{array}{l}-0.219 \\
(0.128)^{*}\end{array}$ & $\begin{array}{l}-0.225 \\
(0.128)^{*}\end{array}$ & $\begin{array}{l}-0.191 \\
(0.103)^{*}\end{array}$ & $\begin{array}{l}-0.199 \\
(0.103)^{* *}\end{array}$ \\
\hline AMI & $-0.089(0.075)$ & $-0.088(0.075)$ & $\begin{array}{l}-0.103 \\
(0.062)^{*}\end{array}$ & $\begin{array}{l}-0.102 \\
(0.062) *\end{array}$ \\
\hline Multi-Vessel PTCA & $\begin{array}{l}0.345 \\
(0.094)^{* * *}\end{array}$ & $\begin{array}{l}0.351 \\
(0.094)^{* * *}\end{array}$ & $\begin{array}{l}0.324 \\
(0.075)^{* * *}\end{array}$ & $\begin{array}{l}0.331 \\
(0.075) * * *\end{array}$ \\
\hline $\begin{array}{l}\text { ICISS } \\
\text { Probability }\end{array}$ & $\begin{array}{l}0.770 \\
(0.238)^{* * *}\end{array}$ & $\begin{array}{l}0.793 \\
(0.238) * * *\end{array}$ & $\begin{array}{l}0.611 \\
(0.199)^{* * *}\end{array}$ & $\begin{array}{l}0.638 \\
(0.199)^{* * *}\end{array}$ \\
\hline Uninsured & $\begin{array}{l}-0.004 \\
(0.002)^{* * *}\end{array}$ & $\begin{array}{l}-0.004 \\
(0.002)^{* * *}\end{array}$ & $-0.002(0.001)$ & $-0.002(0.001)$ \\
\hline Medicaid & $\begin{array}{l}-0.006 \\
(0.002)^{* * *}\end{array}$ & $\begin{array}{l}-0.006 \\
(0.002)^{* * *}\end{array}$ & $\begin{array}{l}-0.004 \\
(0.001)^{* * *}\end{array}$ & $\begin{array}{l}-0.004 \\
(0.001)^{* * *}\end{array}$ \\
\hline Commercial Insurance & $-0.000(0.001)$ & $-0.000(0.001)$ & $0.000(0.001)$ & $0.000(0.001)$ \\
\hline
\end{tabular}

Means of Hospital

Characteristics

Hospital Beds

0.004

0.004

0.003

0.003

Cardiac FTE Nurses

$(0.001)^{* * *}$

$(0.001)^{* * *}$

$(0.001)^{* * *}$

$(0.001)^{* * *}$

Cardiac FTE Nurses

0.002

0.003

0.003

0.004

Not-for-Profit

$(0.001)^{*}$

$(0.001)^{*}$

$(0.001)^{* * *}$

$(0.001)^{* * *}$

0.412

0.409

0.429

0.425 


\begin{tabular}{|c|c|c|c|c|}
\hline & $(0.067)^{* * *}$ & $(0.067)^{* * *}$ & $(0.055)^{* * *}$ & $(0.055)^{* * *}$ \\
\hline Investor-Owned & $\begin{array}{l}0.245 \\
(0.072)^{* * *}\end{array}$ & $\begin{array}{l}0.257 \\
(0.072)^{* * *}\end{array}$ & $\begin{array}{l}0.263 \\
(0.060)^{* * *}\end{array}$ & $\begin{array}{l}0.272 \\
(0.060)^{* * *}\end{array}$ \\
\hline Teaching & $\begin{array}{l}0.163 \\
(0.062)^{* * *}\end{array}$ & $\begin{array}{l}0.149 \\
(0.062)^{* *}\end{array}$ & $0.048(0.051)$ & $0.033(0.051)$ \\
\hline Counties' Median Income & $\begin{array}{l}0.472 \\
(0.285)^{*}\end{array}$ & $\begin{array}{l}0.540 \\
(0.284)^{*}\end{array}$ & $\begin{array}{l}0.419 \\
(0.235)^{*}\end{array}$ & $\begin{array}{l}0.477 \\
(0.235)^{* *}\end{array}$ \\
\hline $2003, Q=3$ & $\begin{array}{l}0.618 \\
(0.053)^{* * *}\end{array}$ & $\begin{array}{l}0.617 \\
(0.053)^{* * *}\end{array}$ & $\begin{array}{l}0.630 \\
(0.043)^{* * *}\end{array}$ & $\begin{array}{l}0.630 \\
(0.043)^{* * *}\end{array}$ \\
\hline 2003, $Q=4$ & $\begin{array}{l}0.741 \\
(0.054)^{* * *}\end{array}$ & $\begin{array}{l}0.739 \\
(0.054)^{* * *}\end{array}$ & $\begin{array}{l}0.769 \\
(0.044)^{* * *}\end{array}$ & $\begin{array}{l}0.766 \\
(0.044)^{* * *}\end{array}$ \\
\hline $2004, Q=1$ & $\begin{array}{l}0.950 \\
(0.056)^{* * *}\end{array}$ & $\begin{array}{l}0.948 \\
(0.056)^{* * *}\end{array}$ & $\begin{array}{l}0.982 \\
(0.046)^{* * *}\end{array}$ & $\begin{array}{l}0.982 \\
(0.046)^{* * *}\end{array}$ \\
\hline $2004, Q=2$ & $\begin{array}{l}1.471 \\
(0.059)^{* * *}\end{array}$ & $\begin{array}{l}1.468 \\
(0.059)^{* * *}\end{array}$ & $\begin{array}{l}1.513 \\
(0.049)^{* * *}\end{array}$ & $\begin{array}{l}1.512 \\
(0.049)^{* * *}\end{array}$ \\
\hline $2004, Q=3$ & $\begin{array}{l}1.653 \\
(0.061)^{* * *}\end{array}$ & $\begin{array}{l}1.650 \\
(0.061)^{* * *}\end{array}$ & $\begin{array}{l}1.694 \\
(0.051)^{* * *}\end{array}$ & $\begin{array}{l}1.692 \\
(0.051)^{* * *}\end{array}$ \\
\hline $2004, Q=4$ & $\begin{array}{l}1.754 \\
(0.064)^{* * *}\end{array}$ & $\begin{array}{l}1.754 \\
(0.064)^{* * *}\end{array}$ & $\begin{array}{l}1.752 \\
(0.053)^{* * *}\end{array}$ & $\begin{array}{l}1.752 \\
(0.053)^{* * *}\end{array}$ \\
\hline Constant & $\begin{array}{l}-6.955 \\
(3.03)^{* *}\end{array}$ & $\begin{array}{l}-7.644 \\
(3.04)^{* * *}\end{array}$ & $\begin{array}{l}-6.537 \\
(2.49)^{* * *}\end{array}$ & $\begin{array}{l}-7.114 \\
(2.49)^{* * *}\end{array}$ \\
\hline Log pseudolikelihood & $-1,727.0$ & $-1,728.7$ & $-2,552.9$ & $-2,556.6$ \\
\hline Number of observations & 3,948 & 3,948 & 5,822 & 5,822 \\
\hline
\end{tabular}

\section{References}

Anspach, R. R. (1993). Deciding Who Lives: Fateful Choices in the Intensive Care Nursery. Berkeley, CA: University of California Press.

Barnett, M. L., Landon, B. E., O’Malley, A. J., Keating, N. L., \& Christakis, N. A. (2011). Predicting Informal Physician Relationships with Administrative Data. Health Services Research, 46(5), 1592-1609. https://doi.org/10.1111/j.1475-6773.2011.01262.x

Bradley, E. H., Holmboe, E. S., Mattera, J. A., Roumanis, S. A., Radford, M. J. \& Krumholz, H. M. (2001). A Qualitative Study of Increasing Beta-Blocker Use After Myocardial Infarction. Journal of the American Medical Association, 285(20), 2604-2611. https://doi.org/10.1001/jama.285.20.2604

Burke, M. A., Fournier, G. M. \& Prasad, K. (2007). The Diffusion of a Medical Innovation: Is Success in the Stars? Southern Economic Journal, 73(3), 588-603. 
https://doi.org/10.2307/20111913

Currie, Janet, MacLeod, W. Bentley, \& Van Parys, Jessica. (2016). Physician Practice Style and Patient Health Outcomes: The Case of Heart Attacks. National Bureau of Economic Research, Working Paper No. 21218. https://doi.org/10.3386/w21218

Cutler, David M. (2007). The lifetime costs and benefits of medical technology. Journal of Health Economics, 26(2007), 1081-1100. https://doi.org/10.1016/j.jhealeco.2007.09.003

Eisenberg, John M. \& Nicklin, David. (1981). Use of diagnostic services by physicians in community practice. Medical Care, 19(3), 297-309. https://doi.org/10.1097/00005650 $-198103000-00005$

Epstein, Andrew J., \& Nicholson, S. (2009). The formation and evolution of physician treatment styles: An application to cesarean sections. Journal of Health Economics, 28(6), 1126-1140. https://doi.org/10.1016/j.jhealeco.2009.08.003

Escarce, José. (1996). Externalities in hospitals and physician adoption of a new surgical technology: An exploratory analysis. Journal of Health Economics, 15(6), 715-734. https://doi.org/10.1016/S0167-6296(96)00501-2

Everitt, Daniel E., Soumerai, Stephen B., Avorn, Jerry, Klapholz, Henry, \& Wessels, Marietjie. (1990). Changing surgical antimicrobial prophylaxis practices through education targeted at senior department leaders. Infection Control and Hospital Epidemiology, 11(11), 578-583. https://doi.org/10.2307/30148431

Freiman, Marc P. (1985). The Rate of Adoption of New Procedures among Physicians: The Impact of Specialty and Practice Characteristics. Medical Care, 23(8), 939-945. https://doi.org/10.1097/00005650-198508000-00001

Grant, Darren \& Mcinnes, Melayne M. (2004). Malpractice Experience and the Incidence of Cesarean Delivery: A Physician-Level Longitudinal Analysis. Inquiry, 41(2), 170-88. https://doi.org/10.5034/inquiryjrnl_41.2.170

Grego, Peter J. \& Eisenberg, John M. (1993). Changing Physicians' Practices. The New England Journal of Medicine, 329(17), 1271-1274. https://doi.org/10.1056/NEJM1993102 13291714

Institute of Medicine. (1990). Clinical practice guidelines: Directions for a new program. Washington, DC: National Academy Press.

Institute of Medicine. (2009). Initial National Priorities for Comparative Effectiveness Research. The National Institutes of Sciences, Engineering, and Medicine.

Jin, L. (2005). Stratification in the Medical Profession. PhD dissertation, Department of Sociology, University of Chicago, Chicago, Illinois.

Kao, J., Vicuna, R., House, J. A., Rumsfield, J. S., Ting, H. H., \& Spertus, J. A. (2008). Disparity in Drug-Eluting Stent Utilization by Insurance Type. American Heart Journal, 156(6), 1133-1140. https://doi.org/10.1016/j.ahj.2008.07.012 
Kuo, D., Gifford, D. R., \& Stein, M. D. (1998). Curbside Consultation Practices and Attitudes among Primary Care Physicians and Medical Subspecialists. Journal of the American Medical Association, 280(10), 905-909. https://doi.org/10.1001/jama.280.10.905

Lichtenberg, F. R. (2009). The quality of medical care, behavioral risk factors, and longevity growth. National Bureau of Economic Research, Working Paper No. 15068. https://doi.org/10.3386/w15068

Lomas, Jonathan, Enkin, Murray, Anderson, Geoffrey M., Hannah, Walter J., Vayda, Eugene \& Singer, Joel. (1991). Opinion Leaders vs Audit and Feedback to Implement Practice Guidelines. Journal of the American Medical Association, 265(17), 2202-2207. https://doi.org/10.1001/jama.1991.03460170056033

Menchik, Daniel A. \& Meltzer, David O. (2010). The Cultivation of Esteem and Retrieval of Scientific Knowledge in Physician Networks. Journal of Health and Social Behavior, 51(2), 137-152. https://doi.org/10.1177/0022146510372231

NCCIH (National Center for Complementary and Integrative Health). (2017). Clinical Practice Guidelines.

Pollack, C. E, Weissman, G., Bekelman, J., Liao, K., \& Armstrong, K. (2012). Physician Social Networks and Variation in Prostrate Cancer Treatment in Three Cities. Health Services Research, 47(1 Pt 2), 380-403. https://doi.org/10.1111/j.1475-6773.2011.01331.x

Robinson, James C. \& Dolan, Emma L. Coronary Angioplasty with Drug-Eluting Stents: Device Costs, Hospital Costs, and Insurance Payments. Berkeley Center for Health Technology, Issue Brief vol. 2, Issues 6. [Online] Available: https://bcht.berkeley.edu/sites/default/files/Vol.2.6.Coronary-Angioblasty.pdf (December 19, 2019)

Rogers, E. M. (1995). Diffusion of Innovation. New York: The Free Press.

Roos, N. P. (1984). Hysterectomy variation in rates across small areas and across physicians' practices. American Journal of Public Health, 74(4), 327-335. https://doi.org/10.2105/AJPH. 74.4.327

Ryan, J. \& Cohen, D. J. (2006). Are Drug-Eluting Stents Cost-Effective? It Depends on Whom You Ask. Circulation, 114, 1736-1744.

https://doi.org/10.1161/CIRCULATIONAHA.105.546010

Shih, C. \& Berliner, E. (2008). Diffusion of New Technology and Payment Policies: Coronary Stents. Health Affairs, 27(6), 1566-1576. https://doi.org/10.1377/hlthaff.27.6.1566

Strauss, S., \& McAlister, F. (2000). Evidence-Based Medicine: A Commentary on Comn Criticisms. Canadian Medical Association Journal, 163, 837-841.

U.S. News and World Report. (2006a). Ultimate Guide to Medical Schools (2nd ed.). Napierville, Ill.: Sourcebooks, Inc. 


\section{Macrothink}

U.S. News and World Report (2006b). http://www.usnews.com/usnews/health/best-hospitals/ rankings/specihqcard.htm

Valente, T. W. (1996). Social Network Thresholds in the Diffusion of Innovations. Social Networks, 18, 69-89. https://doi.org/10.1016/0378-8733(95)00256-1

Wennberg, J. E., Fisher, E. S., \& Skinner, J. (2002). Geography and the Debate Over Medicare Reform. Health Affairs, Web Exclusive. https://doi.org/10.1377/hlthaff.W2.96

\section{Appendix}

Appendix 1. ICISS Survival Probability.

The ICISS is a measure of survival risk that is constructed using patient-level data. For each of the patient's International Classification of Diseases (ICD-9) diagnoses, which include one primary and up to nine secondary, we determine survival risk rations (SRRs) by dividing the number of survivors in each ICD-9 code by the total number of patients with the same ICD-9 code. Then we take the product of the SRRs for each of a patient's diagnoses to create the patient's ICISS value. We use the entire population of patients in our time period to construct the ICISS, not just cardiac patients.

\section{Copyright Disclaimer}

Copyright for this article is retained by the author(s), with first publication rights granted to the journal. This is an open-access article distributed under the terms and conditions of the Creative Commons Attribution license (http://creativecommons.org/licenses/by/4.0/). 